\title{
Mercado popular de alimentos: território da agricultura camponesa e da luta pela soberania alimentar no município de São Gabriel da Palha (ES)
}

\section{Popular food market: the territory of peasant agriculture and the fight for food sovereignty in the municipality of São Gabriel da Palha (ES)}

Mercado popular de alimentos: territorio de la agricultura campesina y de la lucha por la soberanía alimentaria en el municipio de São Gabriel da Palha (ES)

\author{
iD Heider José Boza \\ Universidade Estadual Paulista - São Paulo - São Paulo - Brasil \\ heijboza@yahoo.com.br \\ iD Janaina Francisca de Souza Campos Vinha \\ Universidade Federal do Triângulo Mineiro - Uberaba - Minas Gerais - Brasil \\ janaina.vinha@uftm.edu.br
}

Resumo: Este artigo refletiu sobre a experiência do Mercado Popular de Alimentos, criado no ano de 2011 no município de São Gabriel da Palha (ES) pelo Movimento dos Pequenos Agricultores, caracterizado como um território da agricultura camponesa. Partimos de uma abordagem qualitativa e de procedimentos metodológicos que deram enfoque ao levantamento bibliográfico e documental, à realização de trabalhos de campo e entrevistas com lideranças e camponeses. A discussão proposta revelou o sentido multidimensional e multiescalar do território, aqui representado pelo Mercado Popular de Alimentos, elencando as dimensões política, ambiental, social e econômica que constituem os territórios camponeses na defesa pela Soberania Alimentar e Agroecologia.

Palavras-chave: Soberania alimentar. Mercado Popular de Alimentos. Território camponês. 


\begin{abstract}
This article reflects on the experience of the Popular Food Market, created in 2011 in the municipality of São Gabriel da Palha (ES) by MPA, characterized as a peasant agriculture territory. It was based on a qualitative approach and methodological procedures that focused on the bibliographical and documentary survey, on field work and interviews with leaders and peasants. The proposed discussion revealed the multidimensional and multiscale meaning of the territory, represented here by the Popular Food Market, listing the political, environmental, social and economic dimensions that constitute the peasant territories in defense of Food Sovereignty and Agroecology.
\end{abstract}

Keywords: Food sovereignty. Popular Food Market. Peasant territory.

Resumen: Este artículo reflexionó sobre la experiencia del Mercado Popular de Alimentos, creado en el año 2011 en el municipio de São Gabriel da Paja (ES) por el MPA, caracterizado como un territorio de la agricultura campesina. Se partió de un abordaje cualitativo y de procedimientos metodológicos que se centraron en el levantamiento bibliográfico y documental, la realización de trabajos de campo y entrevistas con líderes y campesinos. La discusión propuesta reveló el sentido multidimensional y multiescalar del territorio, aquí representado por el Mercado Popular de Alimentos, enumerando las dimensiones política, ambiental, social y económica, que constituyen los territorios campesinos en la defensa por la Soberanía Alimentaria y Agroecología.

Palabras clave: Soberanía alimentaria. Mercado Popular de Alimentos. Territorio campesino. 
Mercado popular de alimentos: território da agricultura camponesa e da luta... Janaina Francisca de Souza Campos Vinha • Heider José Boza

\section{Introdução}

No Brasil, aproximadamente 30 milhões de pessoas residem no campo (IBGE, 2010). As famílias camponesas estão distribuídas em mais de 4 milhões de estabelecimentos rurais, responsáveis por mais de $70 \%$ da produção de alimentos que abastecem tanto a cidade quanto o campo (IBGE, 2006). Dos mais de 5 milhões de estabelecimentos agrícolas, quase $85 \%$ são unidades familiares e cerca de $15 \%$ são unidades da agricultura capitalista. Ainda no que diz respeito ao pessoal ocupado, a agricultura camponesa reúne $74 \%$ dos trabalhadores, enquanto o agronegócio emprega em torno de $26 \%$ (IBGE, 2006).

Mesmo representando grande expressão e importância para o abastecimento da população brasileira residente tanto no campo como na cidade, a agricultura camponesa não é preconizada como modelo de desenvolvimento territorial pelo Estado brasileiro. Grande parcela das terras no campo está sob o domínio da agricultura patronal, já que quase 250 milhões de hectares são caracterizados como estabelecimentos capitalistas e cerca 80 milhões de hectares são das famílias camponesas. Na produção agrícola, a desigualdade também é gritante: o agronegócio ocupa 76\% da área agricultável e apresenta um valor bruto anual da produção de $62 \%$; a agricultura camponesa utiliza $24 \%$ da área total e um valor bruto de $38 \%$. No que concerne aos créditos agrícolas, a situação é ainda mais desigual: a agricultura camponesa recebe apenas 15\% dos créditos, enquanto o agronegócio fica com a maior parte (85\%) (IBGE, 2006).

Tais números explicitam, com clareza, a hegemonia do capital no campo. As corporações controlam as políticas de desenvolvimento da agricultura, ficam com a maior parte dos recursos do crédito agrícola e monopolizam os mercados, os capitais e as tecnologias. O agronegócio determina o planejamento, os projetos e os programas da agricultura, subalternizando, expropriando e explorando o campesinato brasileiro. Assim, mesmo responsável 
Mercado popular de alimentos: território da agricultura camponesa e da luta... Janaina Francisca de Souza Campos Vinha . Heider José Boza

pela maior parte da produção dos alimentos destinados à economia doméstica, a agricultura camponesa não é reconhecida como modelo de desenvolvimento para o campo brasileiro, sendo fadada à um cenário de descaso extremamente preocupante, repleta de adversidades (FERNANDES; WELCH; GONÇALVES, 2012).

Em meio à tantas desigualdades, a agricultura camponesa luta e resiste à este modelo excludente e perverso. Uma das formas de enfrentamento e questionamento à este modelo se dá através da implementação de projetos alternativos. O Mercado Popular de Alimentos, experiência pioneira localizada no município de São Gabriel da Palha, Noroeste do Espírito Santo e organizada pelo Movimento de Pequenos Agricultores (MPA), vem promovendo a produção e o acesso da agricultura camponesa aos mercados via fortalecimento da base agroecológica camponesa e da Soberania Alimentar. A reflexão proposta abordou a multidimensionalidade e a multiescalaridade do território, aqui representada pelo Mercado Popular de Alimentos, elencando as dimensões política, ambiental, social e econômica dos territórios camponeses na luta pela Soberania Alimentar. O Mercado Popular, organizado pelo e para o campesinato, incorpora o sentido territorial que diferencia-se dos tradicionais limites político-administrativos definidos pela governança ou pelo perímetro rural, de forma que as relações de poder que o constituem estão baseadas numa lógica camponesa que luta pela sua (re)produção social.

O trabalho baseou-se na abordagem qualitativa e utilizou procedimentos que deram enfoque ao levantamento bibliográfico e documental, à realização de trabalhos de campo nas propriedades camponesas e no Mercado Popular de Alimentos, bem como entrevistas com as famílias e dirigentes do MPA que participaram dessa iniciativa.

Como orientação metodológica, foi empregado neste trabalho o estudo de caso histórico-organizacional (TRIVIÑOS, 1987). Nosso interesse recai sobre uma instituição, nesse caso, o mercado, assim, foram investigados documentos, dados, informações e outros materiais sobre ele. No entanto, para fins de pesquisa, todo esse 
Mercado popular de alimentos: território da agricultura camponesa e da luta... Janaina Francisca de Souza Campos Vinha . Heider José Boza

material carece de uma análise mais refinada, uma vez que as relações históricas entre as famílias e o movimento social, a Soberania Alimentar e a transição agroecológica não são reveladas.

Uma pesquisa calcada no materialismo histórico e dialético, com foco na análise qualitativa dos dados a partir do estudo de caso de uma determinada organização social, não pode ser feita sem a prática do trabalho de campo. A opção por uma pesquisa eminentemente de campo, feita com os "pés no chão", vai ao encontro do postulado por Bernard Kaiser. O geógrafo traz uma série de elementos metodológicos e conceituais para se pensar uma pesquisa de campo que articule os fatos locais aos acontecimentos gerais. Desse modo, o pesquisador afirma que "[...] somente o estudo da inserção do subsistema local no meta-sistema pode dar um sentido à análise local. Logo, à pesquisa de campo" (KAISER, 2006, p. 102).

Ao todo, foram realizadas quatro atividades de campo em três municípios diferentes, a saber: São Gabriel da Palha, Águia Branca e Vila Valério. Foram entrevistadas 11 famílias camponesas e quatro lideranças ligadas ao MPA.

A primeira aconteceu em 2015 e voltou-se ao diálogo com a direção do setor de produção do MPA e com a coordenação do Mercado Popular de Alimentos. A segunda ocorreu em 2016, momento em que foram feitas entrevistas com lideranças e fundadores do MPA no Espírito Santo com o intuito de analisar: 1) as concepções teóricas ou experiências concretas em que se deram o desenvolvimento e a concretização da proposta do Mercado Popular de Alimentos; 2) como a proposta ajuda a viabilizar, na prática, os princípios do plano camponês; 3 ) em que medida a comercialização via Mercado Popular estimula a transição agroecológica e a soberania alimentar das famílias camponesas.

Seguindo as entrevistas, fomos à campo para retomar os processos histórico, social e político do MPA na região noroeste (ES), desde o seu surgimento e desenvolvimento até o seu processo de organização da produção e da comercialização camponesa. Nessa 
Mercado popular de alimentos: território da agricultura camponesa e da luta... Janaina Francisca de Souza Campos Vinha • Heider José Boza

terceira ida à campo, em 2017, cumpriu-se esse objetivo, ou seja, sistematizar o rico processo de lutas que ainda segue à margem da história política.

O último trabalho de campo, realizado no início de 2018, foi o momento de aprofundar algumas questões com as famílias produtoras, tais como: o tempo de escoamento da sua produção para o Mercado Popular; as fontes e tipos de renda; a importância do Mercado Popular na organização de sua produção; e a influência do Mercado Popular no processo de transição agroecológica e no resgate da Soberania Alimentar.

A reflexão apresentada está organizada em duas partes centrais. A primeira discute a lógica que sustenta a agricultura camponesa e a relaciona ao debate da Soberania Alimentar. A segunda versa sobre a multiescalaridade e a multidimensionalidade territorial construída pelo Mercado Popular de Alimentos, um território do campesinato que situa-se na área urbana e possibilita o desenvolvimento de múltiplas dimensões, todas inerentes à racionalidade camponesa.

\section{Agricultura camponesa e Soberania Alimentar: o desa- fio de alimentar os povos do campo e da cidade}

Para discutir o Mercado Popular de Alimentos é imprescindível iniciar um debate sobre os sujeitos envolvidos nesse processo, ou seja, aqueles e aquelas que idealizaram e construíram esse projeto: a agricultura camponesa. Mesmo diante do avanço e consolidação do modo de produção capitalista no campo, o projeto que ancora o mercado procura construir um espaço que cultiva relações e lógicas que se opõem à agricultura capitalista.

Ao elaborar uma teoria econômica a partir do estudo do campesinato russo no início do século XX, Chayanov (1974) revelou que esse grupo deveria ser compreendido com uma racionalidade própria. Uma das suas principais preocupações orbitaram na aná- 
Mercado popular de alimentos: território da agricultura camponesa e da luta... Janaina Francisca de Souza Campos Vinha . Heider José Boza

lise do desempenho econômico dos camponeses, inaugurando uma perspectiva teórica que se dedicou à compreensão do funcionamento das unidades familiares de produção. Foi desvelada a lógica da economia camponesa, a qual não está alinhada ao lucro, mas sim a relação entre o atendimento da satisfação das necessidades familiares e a exploração do trabalho - esta última ajustada pelas famílias camponesas. O limite da produção camponesa é a sobrevivência familiar, e o limite da produção capitalista é o lucro. A agricultura camponesa e agricultura empresarial possuem bases profundamente distintas e que se desenvolvem simultaneamente e contraditoriamente.

O Mercado Popular de Alimentos traduz-se numa alternativa que está baseada na lógica camponesa investigada por Chayanov (1974). Ao produzir através do trabalho familiar, sua economia visa, prioritariamente, a reprodução social da classe. A produção preza pelo cultivo de alimentos sadios, diversidade e uso múltiplo dos recursos naturais, pela policultura, produção de alimentos sem a adição de transgênicos e sem o uso intensivo e abusivo de agrotóxicos, voltada ao abastecimento do mercado interno e alimentício (STÉDILE; CARVALHO, 2010).

O campesinato constitui-se numa classe que, por meio das relações sociais que lhe são específicas, constrói territórios que possibilitam a sua (re)produção social, baseado em relações não capitalistas. O capital se desenvolve de forma contraditória e combinada (OLIVEIRA, 1999), criando e recriando relações não capitalistas de produção no campo através da subordinação da renda da terra ao capital. Mesmo onde não é proprietária da terra, a agricultura capitalista expropria a renda da terra dos camponeses, subordinando-os à sua produção: nos insumos, adubos, fertilizantes, agrotóxicos, sementes; no direcionamento dos créditos; e no controle da circulação e dos preços de mercado, estabelecendo uma relação de dependência.

O campesinato acumulou ao longo de sua história inúmeras experiências de luta e resistência, formando a cultura e a memória dessa classe. No Brasil, a constituição e trajetória do campesinato 
Mercado popular de alimentos: território da agricultura camponesa e da luta... Janaina Francisca de Souza Campos Vinha . Heider José Boza

possui particularidades, caracterizado frente à situação de precariedade, desigualdade e pobreza gerada pelo modo de produção capitalista. $\mathrm{O}$ acesso à terra e à reprodução de formas específicas de produção e sociabilidade são fundamentais para o entendimento da classe no país (WANDERLEY, 2014).

Os movimentos camponeses que se formaram no Brasil e no mundo, principalmente na transição do final da Guerra Fria para o neoliberalismo, herdaram todo o processo acumulativo da classe camponesa em luta. O campesinato, que resistiu às teorias progressistas e conservadoras que pregavam ou previam seu fim, se reorganizou, e a partir dos processos de (re)campesinização, desenvolveu formas de resistência, lógicas, territórios, racionalidades, relações e modos de vida que o manteve enquanto grupo social no curso da história.

Dois fatos interligados e intimamente relacionados à conjuntura política mundial do final da década de 1980 e início de 1990 marcaram essa fase contemporânea de lutas e resistências, reafirmando os camponeses enquanto classe na defesa de seus territórios: a organização da Via Campesina e o debate acerca da Soberania Alimentar.

Mais do que reunir diversas organizações camponesas, a Via Campesina se constitui num movimento que atua em escala global contra o modelo de desenvolvimento assentado na agricultura capitalista mundializada. Para além das fronteiras territoriais e da caracterização interna de cada movimento, a Via Campesina nasceu com uma visão internacionalista de crítica à nova ordem mundial vigente. A Soberania Alimentar é uma construção coletiva que surgiu em 1996 em uma atividade que a Via promoveu em paralelo à Cúpula Mundial da Alimentação, organizada pela FAO (Organização das Nações Unidas para a Alimentação e a Agricultura), em Roma. As mulheres camponesas, na ocasião, se posicionaram contra os governos nacionais e organismos internacionais, cuja apropriação e subversão do conceito de Segurança Alimentar vinha sendo feita por parte da política neoliberal. 
Mercado popular de alimentos: território da agricultura camponesa e da luta... Janaina Francisca de Souza Campos Vinha • Heider José Boza

Em 1946, o geógrafo e médico brasileiro Josué de Castro, formulou em sua obra intitulada Geografia da Fome, a tese de que a fome era um problema social, e não fruto de questões ambientais ou motivadas pela baixa produtividade agrícola de alimentos (CASTRO, 2010). Essa concepção, amplamente combatida pelos Estados Unidos no contexto da Guerra Fria, foi compartilhada pela ONU, fazendo com que o geógrafo fosse o primeiro a presidir a FAO no ato de sua criação. Esse fato fez com que a Segurança Alimentar emergisse enquanto uma política a ser estimulada pela Organização das Nações Unidas e aplicada pelos Estados Nacionais.

Com o advento da mundialização da agricultura e da hegemonia do modelo neoliberal e do agronegócio, a política pública de Segurança Alimentar foi convertida em uma linha auxiliadora por parte das grandes corporações capitalistas do mercado agroalimentar. O papel impulsionador desta política social da FAO se reduziu com o papel dos Estados Nacionais, que passaram a formular políticas de Segurança Alimentar visando atender interesses empresariais, conferindo um caráter meramente assistencialista à uma política pública de alta relevância social que trata diretamente do tema da fome.

Foi exatamente este o tom que os organismos internacionais presentes na Cúpula Mundial da Alimentação da FAO atribuíram à política social da Segurança Alimentar, ajustando essa proposta às demandas do mercado financeirizado, com a liberação do comércio de alimentos para atender aos interesses das grandes empresas e dos organismos internacionais presentes.

É neste cenário que a Via Campesina, em especial às mulheres camponesas, formulou a proposta da Soberania Alimentar, momento em que se denunciou o controle exercido pelas multinacionais sobre a produção e os mercados agroalimentares, bem como os limites institucionais da política de Segurança Alimentar sob a hegemonia neoliberal. 
Mercado popular de alimentos: território da agricultura camponesa e da luta... Janaina Francisca de Souza Campos Vinha • Heider José Boza

Ao compreender a necessidade da Soberania e não apenas da Segurança Alimentar, as organizações camponesas reforçaram a necessidade de se autoafirmarem enquanto sujeitos históricos da produção de alimentos para a população mundial. Aliadas aos trabalhadores urbanos, elas passaram a defender sua autonomia nas formas de plantio e na escolha dos produtos a serem plantados, bem como nas formas de consumi-los, e ainda afirmaram que os governos devem assumir sua responsabilidade nesta política. Além do mais, as organizações camponesas entenderam que a Soberania Alimentar é indissociável da produção em pequena escala, cuja perspectiva está alinhada aos circuitos curtos de distribuição e consumo.

Em 2007, a Via Campesina Internacional, presente na Conferência Mundial da Soberania Alimentar, em Mali, afirmou o seguinte princípio da comercialização camponesa na declaração de Nyélény:

[...] A soberania alimentar dá prioridade para as economias locais e aos mercados locais e nacionais, e outorga o poder aos camponeses e à agricultura familiar, à pesca artesanal e ao pastoreio tradicional. Coloca a produção alimentar, a distribuição e o consumo sobre a base da sustentabilidade ambiental, social e econômica. A soberania alimentar promove o comércio transparente que garante renda digna para todos os povos, e os direitos dos consumidores para controlar sua própria alimentação e nutrição. (Declaração de Nyélény ${ }^{1}$ apud STÉDILE; CARVALHO, 2010, p. 10).

Não há real Soberania Alimentar sem uma autonomia desde a sua produção e comercialização até o consumo das famílias produtoras e consumidoras. A comercialização camponesa, provida de distintas e inúmeras experiências, comparece como alternativa a ser construída pelos movimentos camponeses. Não se trata, apenas, de possibilitar o acesso aos alimentos, mas inclui, tam-

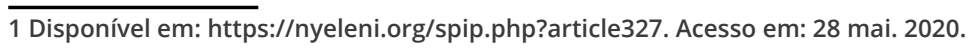


Mercado popular de alimentos: território da agricultura camponesa e da luta... Janaina Francisca de Souza Campos Vinha • Heider José Boza

bém, o direito de construir alternativas de acesso da agricultura camponesa aos mercados (ROSSET, 2006). Da mesma forma que a Agroecologia articula os conhecimentos científicos com os saberes populares, indígenas, quilombolas e camponeses acerca das técnicas agrícolas acumuladas historicamente, o atual estágio da comercialização camponesa, no bojo dos debates acerca da Soberania Alimentar, é também parte da prática histórica da classe camponesa em busca de alternativas para a comercialização justa de seus alimentos.

Com o objetivo de refletir sobre parte da complexidade que integra a racionalidade camponesa, na seção seguir falaremos sobre porque o Mercado Popular de Alimentos no município de São Gabriel da Palha (ES) é entendido como um território de luta pela Agroecologia e Soberania Alimentar.

\section{Mercado Popular de Alimentos em São Gabriel da Palha (ES): território da agricultura camponesa}

Ao conceber o Mercado Popular de Alimentos como um território, é prudente compreendê-lo diante da espacialidade das relações de poder expressas, nesse caso, pelo campesinato (RAFFESTIN, 1993; FERNANDES, 2008). O Mercado Popular de Alimentos, como dito na seção anterior, constitui-se num canal de comercialização alicerçado na lógica camponesa, cujo trabalho familiar, cultivo de alimentos, diversidade de plantios, cuidado com os recursos naturais e o direcionamento para o abastecimento do mercado interno e alimentício, evidenciam as formas de (re)produção social que não se reduzem ao plano econômico, tal como a lógica capitalista se desenvolve.

Na perspectiva analítica adotada neste artigo, o território possui sentidos multidimensional e multiescalar (FERNANDES, 2008). A multidimensionalidade do território dá destaque à sua totalidade e inclui inúmeros aspectos que se relacionam dialeticamente; 
Mercado popular de alimentos: território da agricultura camponesa e da luta... Janaina Francisca de Souza Campos Vinha . Heider José Boza

a multiescalaridade compreende o território para além do espaço de governança, considerando os diversos tipos de relações sociais e territórios que o território nacional abriga em seu interior (FERNANDES, 2008), podendo ser ele uma propriedade rural ou mesmo um mercado alternativo de alimentos, como é o caso.

Discutir a mutidimensionalidade e a multiescalaridade dos territórios é interpretá-los não apenas como um conjunto de sistemas naturais, tampouco reduzi-los a limites políticos-administrativos ou de reconhecimento do poder público, mas reconhecer que a apropriação se dá em escalas e dimensões que transcendem o seu sentido tradicional do espaço de governança controlado pelo Estado-Nação. O Mercado Popular de Alimentos, ao representar a agricultura camponesa da região, é considerado uma extensão dos territórios do campesinato que estão situados nos espaços rurais. A multidimensionalidade manifesta-se na forma do desenvolvimento territorial particular do campesinato, isto é, na lógica camponesa, por isso, forja outros princípios de produção e comercialização que compõem o mercado e atingem inúmeras dimensões. Neste trabalho, serão discutidas as dimensões política, ambiental, social e econômica.

Já a multiescalaridade lança luz aos territórios rurais e urbanos camponeses do MPA na região que participam do Mercado Popular, apreendidos como espaços de luta, enfrentamento e resistência ao modelo hegemônico do agronegócio. Esses territórios podem ser representados tanto pelas pequenas propriedades rurais como também pelo Mercado Popular de Alimentos, que está no centro urbano de São Gabriel da Palha (ES) como um canal alternativo da produção camponesa.

O MPA, atuante no estado desde 1996, estimula uma série de iniciativas alternativas voltadas à produção e comercialização camponesa e à superação da dependência das políticas públicas. São realizadas feiras livres agroecológicas, festas estaduais de sementes crioulas, festas regionais da cultura camponesa, projetos integrados de produção de alimentos agroecológicos e geração de energia - alimergia - e entrega de cestas para grupos de consumi- 
Mercado popular de alimentos: território da agricultura camponesa e da luta... Janaina Francisca de Souza Campos Vinha • Heider José Boza

dores e sindicatos. Em São Gabriel da Palha (ES), há a experiência pioneira do Mercado Popular de Alimentos, foco da análise aqui proposta, concebido como território do campesinato na luta pela soberania alimentar.

O Mercado Popular de Alimentos surgiu em 2011 na cidade, localizado na região Noroeste (ES) (Mapa 1). Seu nascimento está ancorado na necessidade da agricultura camponesa em dar respostas às demandas e desafios decorrentes da transição agroecológica. O mercado visa, ainda, superar o modelo do agronegócio da cultura do café e abrir espaço à produção de alimentos sadios, sem a dependência de mercados institucionais ou de atravessadores.

\section{Mapa 1 - Município de São Gabriel da Palha (ES)}

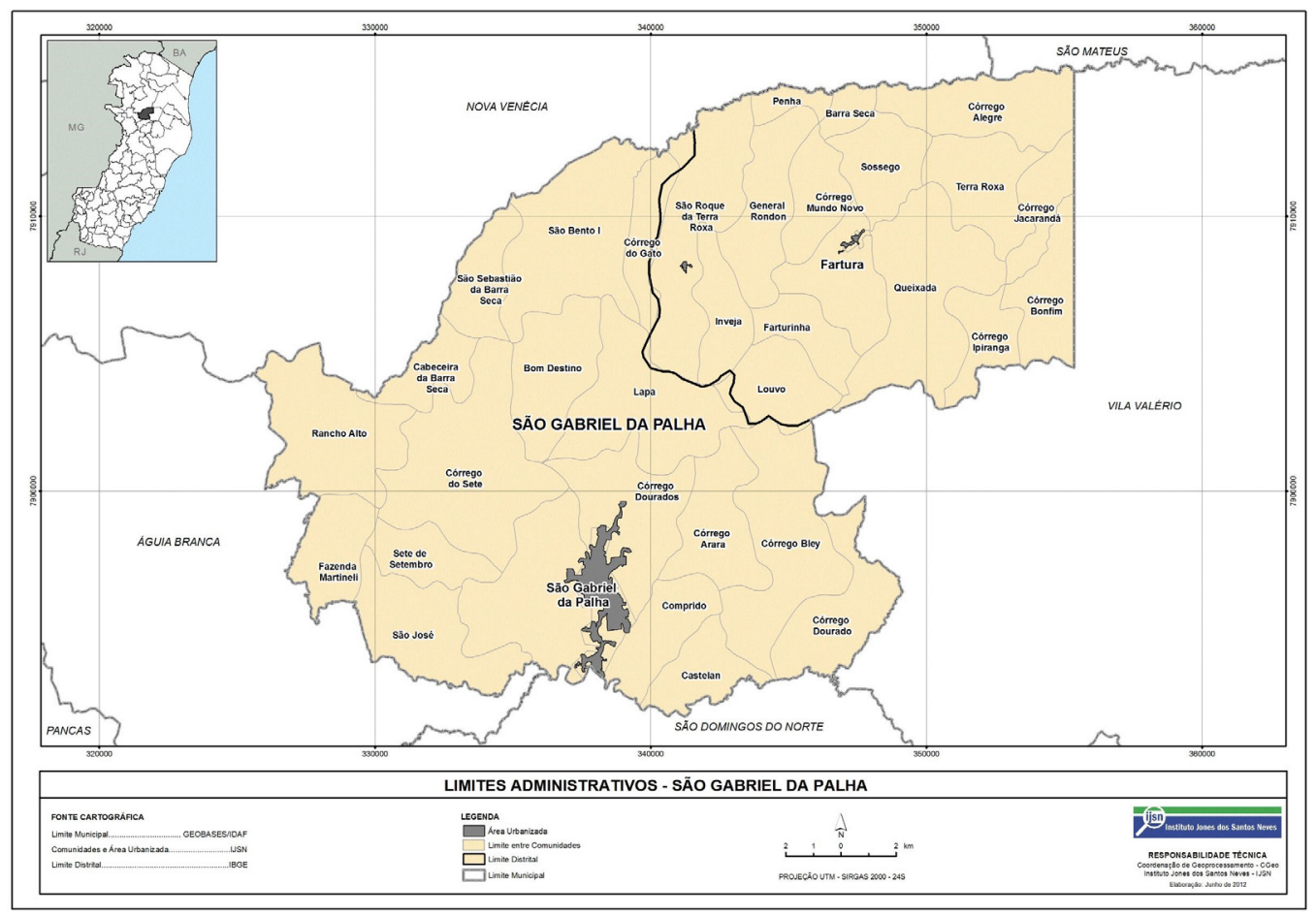

Fonte: Instituto Jones dos Santos Neves (IJSN) - Secretaria de Estado de Economia e Planejamento (SEP) do Espírito Santo. http://www.ijsn.es.gov.br/mapas/ 
Mercado popular de alimentos: território da agricultura camponesa e da luta... Janaina Francisca de Souza Campos Vinha . Heider José Boza

A dimensão política é considerada como uma das grandes responsáveis pela existência e avanço do Mercado Popular, já que a organização do campesinato nessa região é o que, de fato, viabilizou as condições necessárias para a efetiva construção desse território.

Durante um período, as feiras livres atuaram como esse espaço alternativo camponês. Mesmo com a continuidade e o estímulo dessa alternativa, procurou-se por saídas para dar vazão, em maiores escalas, à produção camponesa. Houve a possibilidade real dos Programas de Segurança Alimentar e Nutricional estimularem a diversificação e a organização da produção agrícola, garantindo a venda e o preço acima do mercado. Entretanto, o Plano Camponês e a Soberania Alimentar, para se realizarem na estratégia da organização, demandam iniciativas independentes do poder público. Como se confirmou com as políticas públicas para a agricultura camponesa, esses Programas não asseguraram as bases da produção em eventuais acirramentos dos conflitos, como no caso do atual movimento golpista e de desmonte das políticas públicas e ministérios.

Assim, após debates e estudos de experiências camponesas pelo mundo, foi inaugurado, em novembro de 2011, o Mercado Popular de Alimentos. Da tomada dessa decisão política, surgiu o desafio de estimular a comercialização e a diversificação da produção, que não encontra espaço nos mercados convencionais - a não ser que se encaixe nos padrões de produção (pacotes de insumos, sementes e agrotóxicos) e nos padrões da comercialização (gêneros padronizados para o consumo em massa e a forte presença do atravessador).

Tradicionalmente, a cultura agrícola predominante no Noroeste do estado é o café conilon. O cultivo dessa cultura disseminada na região nas décadas de 1930 e 1940, período da ocupação territorial pelas famílias imigrantes camponesas, foi inicialmente com a introdução do café do tipo arábica. Além do café, diversos outros gêneros agrícolas também eram produzidos e utilizados na 
Mercado popular de alimentos: território da agricultura camponesa e da luta... Janaina Francisca de Souza Campos Vinha . Heider José Boza

alimentação própria, na alimentação das criações e até mesmo na troca de produções com outras famílias.

A partir do desenvolvimento da Revolução Verde na região, com a introdução da variedade conilon, considerado tipo de maior produtividade, se instaurou a monocultura. As famílias pararam de plantar os alimentos e começaram a dedicar toda sua produção ao plantio do café. Por meio da renda obtida com a comercialização do café, as famílias passaram a comprar nos supermercados os demais itens, inclusive os alimentos antes produzidos.

Até a criação do mercado, a maioria das famílias comercializava o café com atravessadores locais, como a cooperativa Cooabriel, ou então se deslocavam por muitos quilômetros para vender no CEASA. O próprio acesso às feiras livres era limitado, tendo em vista que os grandes centros urbanos eram distantes e os camponeses não tinham condições objetivas e materiais diárias de mobilidade.

Diante do avanço e impulso do agronegócio na região, o principal desafio foi diversificar a produção a partir de um modelo de produção que deixasse de priorizar a monocultura e as commodities. Inicialmente, o movimento estimulou - e ainda estimula - a participação junto às feiras-livres, mas a partir das formulações e da disseminação da proposta do Plano Camponês, foram elaboradas formas de comercialização alternativas que se adequassem às demandas concretas das famílias camponesas da região.

As dimensões política e social forjadas na construção do Mercado Popular são importantes para a compreensão do território do campesinato que o mercado representa. A presença do MPA como agente articulador político é considerado pelos entrevistados elemento-chave para a existência não só do mercado, mas para o estímulo e convencimento dos camponeses a integrarem um projeto que promove a Soberania Alimentar e a produção agroecológica.

A importância das organizações sociais para a classe trabalhadora é histórica. No caso específico do agronegócio da cultura café, perpetuada por décadas na região, implementar a agroecologia é 
Mercado popular de alimentos: território da agricultura camponesa e da luta... Janaina Francisca de Souza Campos Vinha . Heider José Boza

tarefa que exige grande esforço. O processo de transição agroecológica, convencionalmente transmitida de forma verticalizada do técnico para o camponês, por meio do extensionismo clássico, é ineficaz. O método de Camponês a Camponês (CAC), que chegou em Cuba em 1997, propõe elevar o campesinato como sujeito deste processo, ou seja, é a partir da experiência agroecológica de uma família que as demais passam a conhecer os resultados e se interessar (SOSA et al., 2012). Foi através do CAC que o MPA agregou e ampliou o número de famílias participantes desde a criação do mercado, em 2011. Como será evidenciado, são cerca de 188 famílias que comercializam junto ao mercado.

Assim, é através do MPA, com o Plano Camponês, que foi formulado um projeto estratégico do e para o campesinato brasileiro que se opõe ao modelo do agronegócio. O Plano envolve a identidade camponesa, a agroecologia, o resgate das sementes crioulas, a biodiversidade, a cultura camponesa e a produção de alimentos para o campo e cidade (SILVA, 2016). É com esse projeto que o MPA desenvolve suas ações junto ao Mercado Popular de Alimentos, o qual constitui parte do Programa Camponês. O Programa Camponês aposta em políticas que promovem a produção camponesa e o abastecimento popular, construído através de uma aliança de classe entre o campo e a cidade. Ele é parte do Plano Camponês, uma luta popular que teve sua primeira experiência no Rio Grande do Sul e está alicerçado na produção de alimentos e na transição agroecológica; no apoio à logística para o beneficiamento e comercialização de alimentos; e na articulação entre produção e consumo (SILVA, 2016).

A participação e articulação do campesinato junto ao MPA revela o sentido político territorial do mercado, uma vez que sua criação surge com o trabalho de base do movimento social. Somase a isso o fato que desde a sua inauguração, o Mercado Popular de Alimentos é uma experiência autogestionada pelo campesinato - em todos os sentidos. A coordenação técnica e política, a gestão, o trabalho manual e outros serviços são executados pelo campesinato que participa do MPA. Sua sustentação é independente, ou 
Mercado popular de alimentos: território da agricultura camponesa e da luta... Janaina Francisca de Souza Campos Vinha . Heider José Boza

seja, tem-se autonomia em relação a governos ou políticas públicas, não demandando de recursos externos para sua manutenção, pagamento dos salários, contas e demais despesas. Apenas o prédio do Mercado Popular não foi adquirido com recursos próprios, pois era um prédio público que seria abandonado, e então foi solicitado e conquistado junto ao governo estadual pelas famílias camponesas de São Gabriel da Palha. Há alguns anos, o prédio teve sua estrutura condenada e o Mercado Popular teve que mudar de endereço, funcionando atualmente em imóvel alugado, mas ainda assim mantendo-se com recursos próprios.

A agroecologia é um princípio fundamental do MPA e contribui significativamente nesse processo de diversificação produtiva, questão basilar na construção do Mercado Popular de Alimentos e que auxiliou na compreensão da dimensão ambiental. Desde a sua fundação, o grupo que coordenou a iniciativa deliberou que nesse espaço seriam comercializados apenas alimentos agroecológicos. Esta decisão não se deu apenas porque a agroecologia é um dos princípios básicos da organização, mas porque na região Noroeste (ES), assim como em São Gabriel da Palha, o movimento buscava valorizar as famílias que, apesar das dificuldades, estavam se desafiando à produção agroecológica.

É importante destacar que assim como outras dimensões, a ambiental não descola-se de outras, como a social e a cultural, por exemplo. As práticas agroecológicas apoiam-se numa visão de produção que não fragmentam sociedade e natureza, pelo contrário, buscam integrar e romper o isolacionismo das ciências, dos saberes e dos conhecimentos impugnados pelo paradigma cartesiano. A agroecologia participa de um processo de mudança paradigmática que (re)organiza a sociedade, a civilização e a cultura (CAPORAL; COSTABEBER; PAULUS, 2006). Ao valorizar o saber camponês em suas relações de cultivar e produzir alimentos, retomam-se práticas tradicionais de manejo da agricultura que fazem parte do campesinato, ou seja, é um elemento cultural, sendo, ao mesmo tempo, social e natural. "Mais do que tratar de processos naturais, trata-se, aqui, de processos socioculturais, de uma cons- 
Mercado popular de alimentos: território da agricultura camponesa e da luta... Janaina Francisca de Souza Campos Vinha • Heider José Boza

trução humana. Neste sentido, convém lembrar que o homem é um ser cultural, e é também pela cultura que ele se distingue dos demais seres vivos." (CAPORAL; COSTABEBER; PAULUS, p. 68).

Numa região que ainda é marcadamente dominada pelo agronegócio do café conilon, em que aparentemente é lucrativo produzir sob os moldes da agricultura convencional, os desafios para a transição agroecológica são enormes. Não basta que sejam feitas formações, seminários, oficinas ou até mesmo que se garanta a assistência técnica. É preciso existir uma demanda real de consumo e de produção, com mercados para que esses produtos possam ser comercializados e reconhecidos como agroecológicos. O MPA, ao construir as bases para o Mercado Popular de Alimentos, forjou uma experiência catalisadora para a transição agroecológica na região:

[...] das cento e tantas famílias que comercializam no Mercado Popular, e que estão ali todas as semanas, ou várias vezes por semana, ela se depara com um conjunto de alimentos produzidos sem agrotóxicos. Então, quer dizer, a família chega ali, dá de cara com um monte de produtos sem veneno e ela fala: bom, é possível produzir sem veneno, e se eu lá em casa não consegui produzir o tomate sem veneno, teve agricultor aqui que produziu. Então, vai desmontando esse imaginário de que sem veneno não produz. Acho que isso é uma primeira coisa. Uma segunda coisa: à medida que a família planta, produz sem veneno, encontra um lugar pra vender, e consegue gerar renda, isso também anima a família a fazer mais [...]. Então, nessa coisa de ter onde ir vender o produto sem agrotóxico, ainda que tenham aspectos estéticos inferiores ao produto convencional, o público que vem consumir procura por este tipo de produto (Entrevistado 2, São Gabriel da Palha, 2016).

O Mercado Popular, por dar visibilidade e vazão à produção agroecológica e incentivar a cultura camponesa e a produção de alimentos, também garantiu às famílias suas próprias soberanias alimentares, direito esse que Ihes foi expropriado historicamente 
Mercado popular de alimentos: território da agricultura camponesa e da luta... Janaina Francisca de Souza Campos Vinha . Heider José Boza

com a territorialização do agronegócio na região. Para os dirigentes do Movimento, esta Soberania Alimentar advém da possibilidade de decidir o que plantar, como plantar e de se alimentar dessa cultura, mas também da possibilidade de, através do Mercado Popular, comprar e trocar alimentos e sementes que não são cultivados em suas propriedades.

A dimensão territorial econômica é outra questão relacionada ao mercado. À medida que as famílias deixam de comprar nos mercados convencionais, acabam gerando renda, não ficando dependentes da renda do café para adquirir os demais alimentos e bens. Algumas famílias relatam que não cultivam mais monocultura, pois estão se dedicando à produção de alimentos. Historicamente, o campesinato cultiva gêneros alimentícios, voltados ao autoconsumo e à pequena produção, sendo esse um elemento que caracteriza a lógica camponesa. Além disso, as famílias também relataram que se sentem mais valorizadas ao voltar a consumir o próprio alimento, não precisando buscar por alimentos básicos na cidade. Dessa maneira, promover a Soberania Alimentar é, também, promover a soberania territorial, de forma a resgatar a autonomia e o direito de plantar, produzir e comer bem.

Em um levantamento realizado em 2015, identificou-se que cerca de 188 famílias comercializavam através do Mercado Popular - algumas com maior e outras com menor frequência. Essas famílias estão distribuídas majoritariamente em São Gabriel da Palha, mas também em Águia Branca, Vila Valério, Pancas e Governador Lindemberg. Há ainda camponeses de outras regiões que pontualmente entregam alimentos ao mercado, como Barra de São Francisco, Nova Venécia, Água Doce do Norte, São Mateus e Marechal Floriano. Com base nos dados de 2016, cerca de 70\% da produção do mercado advém de São Gabriel da Palha, foco da nossa reflexão.

A diversidade de produtos ofertados revela a dimensão produtiva do território camponês: neste mesmo ano, foram comercializados 321 produtos diferentes, entre frutas, verduras e legumes, 
Mercado popular de alimentos: território da agricultura camponesa e da luta... Janaina Francisca de Souza Campos Vinha • Heider José Boza

diversos tipos de pães, biscoitos, roscas, macarrão, queijos, doces, compotas e cachaças, além do artesanato.

A diversidade de cultivos, o trabalho familiar, a produção de alimentos sadios sem agrotóxicos e o abastecimento do mercado interno são algumas das características da lógica camponesa e que foi lançada pelo Mercado Popular de Alimentos. Para se ter uma ideia da diversidade da agricultura camponesa, em apenas uma das propriedades que integram o processo de produção e comercialização destinada ao mercado, observou-se uma grande variedade de culturas como alface, couve, couve-flor, rúcula, espinafre, feijão, inhame, cenoura, beterraba, aipim, jaca, cacau, manga e banana, além da criação de porcos e galinhas, todas cultivadas com práticas agroecológicas que advém de um processo de transição que já dura, pelo menos, 10 anos. Esse processo de transição agroecológica é um dos grandes desafios das famílias, uma vez que o solo ocupado pelo café, que perdurou durante décadas na região, carece de um processo gradual de desintoxicação. Para essa transição, a assistência técnica prestada pelo MPA para as famílias é considerada de extrema importância.

A questão da legislação sanitária é tratada como um dos gargalos para o escoamento da produção camponesa. As leis sanitárias relativas à agricultura, que são hoje de competência do Ministério da Agricultura, Pecuária e Abastecimento - instrumento de Estado ligado ao Agronegócio - vetam a produção tradicional e cultural camponesa, já que elas não se alinham ao atual modelo sanitarista. De acordo com os dirigentes entrevistados, tais normativas impedem o desenvolvimento da produção e vetam a circulação da produção agroecológica nos mercados formais.

O cooperativismo e a criação de uma feira livre fixa conjugam-se como possibilidades de regulamentação e institucionalização do Mercado Popular de Alimentos. Ambos os modelos estão na concepção política, porém, para serem formalizados e assim aces- 
Mercado popular de alimentos: território da agricultura camponesa e da luta... Janaina Francisca de Souza Campos Vinha . Heider José Boza

sar mercados institucionais que antes eram acessados via PAA², a organização do mercado precisa encarar a legislação e regulamentar as unidades familiares produtivas.

Conforme o levantamento das vendas de 2015, do total das variedades comercializadas, 142 necessitam de inspeção sanitária e 180 agroindústrias familiares precisam ser regularizadas - 0 maior volume de vendas em dinheiro advém de produtos como pães, bolos, biscoitos e queijos. Se, por um lado, a informalidade do Mercado Popular permite a comercialização de gêneros da cultura camponesa que não se enquadram na legislação vigente, por outro, a institucionalização do Mercado Popular possibilitaria ampliar o acesso à mercados institucionais e políticas públicas de comercialização, o que atualmente é difícil diante do nível de informalidade.

O território é fruto de ações históricas que se materializam ao longo do tempo, e também produto de dinâmicas socioespaciais de grupos que se apropriam socialmente do espaço (Saquet, 2009). O Mercado Popular de Alimentos é um território construído pelo campesinato que retrata múltiplas variáveis e relações recíprocas e unitárias que remetem à lógica camponesa de produção. Essas variáveis podem ser analisadas interpretando a multidimensionalidade ao eleger algumas delas para o estudo, o que não implica em desconsiderar outras dimensões que integram o território (FERNANDES, 2008).

Adotar a multidimensionalidade e multiescalaridade como abordagens analíticas para a compreensão do Mercado Popular de Alimentos auxilia na compreensão e aprofundamento dos territórios camponeses, já que as dimensões são compostas pelas condições construídas pelos sujeitos em suas práticas cotidianas sociais. O mercado, seja pela dimensão política, social, ambiental ou econômica, ao direcionar-se para a diversificação e comercialização da produção via mercado alternativo, fortalece a Soberania

\footnotetext{
2 Criado em 2003, o PAA sofreu uma redução de $40 \%$ no seu orçamento, diminuendo de R\$ 478 para R\$294 milhões. Segundo a Articulação Semiárido Brasileiro (ASA), o número de pessoas atendidas também diminuiu em 55\%. Disponível em: https://www. brasildefato.com.br/2017/08/29/corte-no-programa-de-aquisicao-de-alimentos-ameaca-familias-do-semiarido/. Acesso em: 03 fev. 2017.
} 
Mercado popular de alimentos: território da agricultura camponesa e da luta... Janaina Francisca de Souza Campos Vinha • Heider José Boza

Alimentar e a Agroecologia, reafirma os territórios camponeses de produção, localizados nas áreas rurais de plantio e cria territórios do campesinato na cidade. Da mesma forma, ao compreender o Mercado Popular como um território para além do espaço contido na área rural, considera-se que a cidade também é um espaço apropriado e construído que projeta relações sociais e territórios que remetem à lógica camponesa de produção, cuja (re)produção social se sobrepõe à racionalidade da agricultura capitalista.

\section{Considerações finais}

O Mercado Popular de Alimentos revelou os sentidos multiescalar e multidimensional do território da agricultura camponesa e da luta pela Soberania Alimentar, elencando as dimensões política, ambiental, social e econômica presentes nos espaços rurais e urbanos. Ele trouxe à tona a racionalidade camponesa, ancorada num projeto de vida que não se restringe à esfera econômica, adentrando múltiplas e diversas nuances na sua relação com a natureza e a sociedade.

Ao discutir a experiência do Mercado Popular de Alimentos dentro do escopo da multidimensionalidade territorial, é importante destacar que embora essa perspectiva tenha prezado pela totalidade na compreensão dos processos sobre a questão agrária, muitas outras questões ainda colocam-se no horizonte e carecem ser analisadas. Uma delas refere-se, por exemplo, à relação campo/cidade e/ou rural/urbano, a qual pode ser redimensionada a partir de um estudo sobre a criação do mercado situado no Centro do município. Os preços praticados e os circuitos curtos de comercialização são outras discussões que não foram refinadas neste artigo, mas que, igualmente, podem ser exploradas e têm o potencial de qualificar a reflexão proposta.

Outra questão também está ligada aos desafios práticos da transição agroecológica e de autossustentação do mercado. A 
Mercado popular de alimentos: território da agricultura camponesa e da luta... Janaina Francisca de Souza Campos Vinha • Heider José Boza

presente pesquisa foi desenvolvida num momento em que dois fatores a influenciaram decisivamente: a combinação de um período longo de estiagem na região e o desmonte progressivo das políticas públicas para o campo. Esses fatores podem "desviar" os camponeses para o mercado do café. Assim, a organização e a manutenção das famílias na base produtiva agroecológica precisaram ser intensificadas, mas sem apoio institucional algum. A ampliação do escopo de atuação do Mercado Popular, enviando a produção camponesa para as feiras do MPA em todo o estado, ajudou na garantia de renda e escoamento da produção para essas famílias.

A perda, por razões estruturais, do prédio público onde funcionava o mercado, e a necessidade de locação de outro imóvel, também impôs mais ônus à organização do MPA. A integração, por parte do Movimento, de iniciativas de produção e comercialização alternativas, até via mercados institucionais, foi elemento-chave para a perpetuação dessa experiência ainda em construção.

Estas são questões práticas do cotidiano da organização popular que integram os desafios frente ao contexto político-nacional e reforçam a necessidade da análise multidimensional e multiescalar do território em relevo.

\section{Referências}

CAPORAL, F. R.; COSTABEBER, J. A.; PAULUS, G. Agroecologia: matriz disciplinar ou novo paradigma para o desenvolvimento rural sustentável. Brasília: [s.n.], 2006. Disponível em: http://biblioteca. emater.tche.br:8080/pergamumweb/vinculos/000005/000005f5. pdf. Acesso em: 10 dez. 2018.

CASTRO, J. Geografia da fome: o dilema brasileiro: pão ou aço. 10. Ed. Rio de Janeiro: Civilização Brasileira, 2010.

CHAYANOV, A. V. La organización de la unidad económica campesina. Buenos Aires: Nueva Visión, 1974. 
Mercado popular de alimentos: território da agricultura camponesa e da luta... Janaina Francisca de Souza Campos Vinha • Heider José Boza

FERNANDES, B. M. Entrando nos territórios do território. In: PAULINO, E. T.; FABRINI, J. E. Campesinato e territórios em disputa. São Paulo: Expressão Popular: 2008. p. 273-302.

FERNANDES, B. M; WELCH, C. A; GONÇALVES, E. C. Políticas fundiárias no Brasil: uma análise geo-histórica da governança da terra no Brasil. Roma: International Land Coalition, 2012.

IBGE. Censo agropecuário 2006. Disponível em: https://biblioteca.ibge.gov.br/visualizacao/periodicos/51/agro_2006.pdf-. Acesso em: 01 jul. 2016.

IBGE. Censo demográfico 2010. Disponível em: http://www. cidades.ibge.gov.br/xtras/temas.php?lang=\&codmun=315770\&idtema $=90 \&$ search=minas-gerais $\mid$ santa-juliana $\mid$ censo-demografico-2010:-resultados-da-amostra-caracteristicas-da-populacao-. Acesso em: 03 jul. 2016.

KAISER, B. O geógrafo e a pesquisa de campo. Boletim Paulista de Geografia, São Paulo, n. 84, p. 93-104, 2006.

OLIVEIRA, A. U. de. A geografia agrária e as transformações territoriais recentes no campo brasileiro. In: CARLOS, Ana F. A. (Org.). Novos caminhos da geografia. São Paulo: Contexto, 1999. p. 63-137.

RAFFESTIN, C. Por uma geografia do poder. São Paulo: Ática, 1993.

ROSSET, P. Alternativas à política fundiária de mercado: reforma agrária e soberania alimentar. In: SAUER, S.; PEREIRA, J. M. (Org.). Capturando a terra: Banco Mundial, políticas fundiárias neoliberais e reforma agrária de mercado. São Paulo: Expressão Popular: 2006. p. 315-342.

SAQUET, M. A. Por uma abordagem territorial. In: SAQUET, M. A.; SPOSITO, E. S. (Org.) Território e Territorialidades: teorias, processos e conflitos. 1. ed. São Paulo: Expressão Popular, 2009. p. 73-94. 
Mercado popular de alimentos: território da agricultura camponesa e da luta... Janaina Francisca de Souza Campos Vinha • Heider José Boza

SILVA, V. I. Plano camponês e a relação campo e cidade. 2016. Disponível em: http://mpabrasil.org.br/2106-2/. Acesso em: 17 out. 2017.

SOSA, M. B. et al. Revolução agroecológica: o movimento de camponês a camponês na ANAP em Cuba. 1. ed. São Paulo: Outras Expressões, 2012.

STÉDILE, J. P.; CARVALHO, H. M. de. Soberania alimentar: uma necessidade dos povos. 2010. Disponível em: http://www. ecodebate.com.br/2011/03/25/soberania-alimentar-uma-necessidade-dos- povosartigode-joao-pedro-stedile-e-horacio-martins-de-carvalho. Acesso em: 14 jul. 2015.

TRIVIÑOS, A. N. S. Introdução a pesquisa em Ciências Sociais: a pesquisa qualitativa em Educação. São Paulo: Atlas, 1987.

WANDERLEY, M. N. B. O campesinato brasileiro: uma história de resistência. Revista de Economia e Sociologia Rural, Brasília, v. 52, suppl.1, p. 25-44, 2014.

Agradecemos ao Programa de Pós-Graduação em Desenvolvi-mento Territorial na América Latina e Caribe (TerritoriAL-UNESP) e a Coordenação de Aperfeiçoamento de Pessoal de Nível Superior (Capes) 2016.

\section{Declaração de contribuição individual}

Todos os autores ofereceram substanciais contribuições científicas e intelectuais ao estudo. As tarefas de concepção e design do estudo, preparação e redação do manuscrito, bem como, revisão crítica foram desenvolvidas em grupo. O primeiro autor, Heider José Boza, ficou especialmente responsável pela aquisição de dados e suas interpretações e análises, bem como dos procedimentos técnicos. A segunda autora, Janaina Francisca de Souza Campos Vinha, ficou responsável pelo desenvolvimento teórico-conceitual e pela tradução do resumo. 
Mercado popular de alimentos: território da agricultura camponesa e da luta... Janaina Francisca de Souza Campos Vinha • Heider José Boza

Heider José Boza - Possui graduação em Geografia pela Universidade Federal do Espírito Santo (UFES) e mestrado em Geografia pelo Programa de Pós-Graduação em Desenvolvimento Territorial na América Latina e Caribe (TerritoriAL-UNESP).

OrcidD: https://orcid.org/0000-0001-7205-3767

Janaina Francisca de Souza Campos Vinha - Possui graduação e doutorado em Geografia pela Universidade Estadual Paulista (UNESP), Faculdade de Ciências e Tecnologia, Presidente Prudente. Realizou estágio na University of Manitoba, Canadá. Atualmente é docente na Universidade Federal do Triângulo Mineiro e do Programa de Pós-Graduação em Desenvolvimento Territorial na América Latina e Caribe (TerritoriAL-UNESP).

OrclD: https://orcid.org/0000-0002-8763-4465

Recebido para publicação em 20 de abril de 2020 Aceito para publicação em 16 junho de 2020 Publicado em 07 de julho de 2020 